\title{
Cladistics
}

\section{Is The Amphibian Tree of Life really fatally flawed?}

\author{
Darrel R. Frost ${ }^{1 *}$, Taran Grant ${ }^{2}$, Julian Faivovich ${ }^{3}$, Raoul H. Bain ${ }^{1}$, Alexander Haas ${ }^{4}$, \\ Celio F. B. Haddad ${ }^{3}$, Rafael O. de Sa $^{5}$, Alan Channing ${ }^{6}$, Mark Wilkinson ${ }^{7}$, \\ Stephen C. Donnellan ${ }^{8}$, Christopher J. Raxworthy ${ }^{1}$, Jonathan A. Campbell ${ }^{9}$, \\ Boris L. Blotto $^{10}$, Paul Moler ${ }^{11}$, Robert C. Drewes ${ }^{12}$, Ronald A. Nussbaum ${ }^{13}$, \\ John D. Lynch ${ }^{14}$, David M. Green ${ }^{15}$ and Ward C. Wheeler ${ }^{16}$
}

\begin{abstract}
${ }^{1}$ Division of Vertebrate Zoology (Herpetology), American Museum of Natural History, New York, NY 10024, USA; ${ }^{2}$ Faculdade de Biociências, Pontificia Universidade Católica do Rio Grande do Sul (PUCRS), Av. Ipiranga 6681, 90619-900 Porto Alegre, RS, Brazil; ${ }^{3}$ Departamento de Zoologia, Instituto de Biociências, Universidade Estadual Paulista (UNESP), Caixa Postal 199, 13506-900 Rio Claro, São Paulo, Brazil; ${ }^{4}$ Biocenter Grindel and Zoological Museum Hamburg, Martin-Luther-King-Platz 3, D-20146 Hamburg, Germany, ${ }^{5}$ Department of Biology, University of Richmond, Richmond, VA 23173-0001, USA; ${ }^{6}$ Department of Biodiversity and Conservation Biology, University of the Western Cape, Private Bag X17, Bellville 7535, South Africa; ${ }^{7}$ Department of Zoology, The Natural History Museum, Cromwell Road, London SW7 5BD, UK; ${ }^{8}$ South Australia Museum, Evolutionary Biology Unit, North Terrace, Adelaide 5000, South Australia; ${ }^{9}$ Department of Biology, University of Texas at Arlington, TX 76019-0001, USA; ${ }^{10}$ Division Herpetología, Museo Argentino de Ciencias Naturales "Bernardino Rivadavia", Angel Gallardo 470, 1405 Buenos Aires, Argentina; ${ }^{11} 7818$ SW CR-346, Archer, FL 32618, USA; ${ }^{12}$ Department of Herpetology, California Academy of Sciences, 875 Howard Street, San Francisco, CA $94103-$ 3009, USA; ${ }^{13}$ Museum of Zoology and Department of Ecology and Evolutionary Biology, University of Michigan, 1109 Geddes Avenue, Ann Arbor, MI 48109-1079, USA $;{ }^{14}$ Instituto de Ciencias Naturales, Universidad Nacional de Colombia, Apartado 7495, Bogota, Colombia; ${ }^{15}$ Redpath Museum, McGill University, 859 Sherbrooke Street West, Montreal, Quebec H3A 2K6, Canada; ${ }^{16}$ Division of Invertebrate Zoology, American Museum of Natural History, New York, NY 10024, USA
\end{abstract}

Accepted 4 June 2007

\begin{abstract}
Wiens (2007, Q. Rev. Biol. 82, 55-56) recently published a severe critique of Frost et al.'s (2006, Bull. Am. Mus. Nat. Hist. 297, 1-370) monographic study of amphibian systematics, concluding that it is "a disaster" and recommending that readers "simply ignore this study". Beyond the hyperbole, Wiens raised four general objections that he regarded as "fatal flaws": (1) the sampling design was insufficient for the generic changes made and taxonomic changes were made without including all type species; (2) the nuclear gene most commonly used in amphibian phylogenetics, RAG-1, was not included, nor were the morphological characters that had justified the older taxonomy; (3) the analytical method employed is questionable because equally weighted parsimony "assumes that all characters are evolving at equal rates"; and (4) the results were at times "clearly erroneous", as evidenced by the inferred non-monophyly of marsupial frogs. In this paper we respond to these criticisms. In brief: (1) the study of Frost et al. did not exist in a vacuum and we discussed our evidence and evidence previously obtained by others that documented the non-monophyletic taxa that we corrected. Beyond that, we agree that all type species should ideally be included, but inclusion of all potentially relevant type species is not feasible in a study of the magnitude of Frost et al. and we contend that this should not prevent progress in the formulation of phylogenetic hypotheses or their application outside of systematics. (2) Rhodopsin, a gene included by Frost et al. is the nuclear gene that is most commonly used in amphibian systematics, not RAG-1. Regardless, ignoring a study because of the absence of a single locus strikes us as unsound practice. With respect to previously hypothesized morphological synapomorphies, Frost et al. provided a lengthy review of the published evidence for all groups, and this was used to inform taxonomic decisions. We noted that confirming and reconciling all morphological transformation series published among previous studies needed to be done, and we included evidence from the only published data set at that time to explicitly code morphological characters (including a number of traditionally applied synapomorphies from adult morphology) across the bulk of the diversity of amphibians (Haas, 2003, Cladistics 19, 23-90).
\end{abstract}

\footnotetext{
*Corresponding author:

E-mail address: frost@amnh.org
}

(C) The Willi Hennig Society 2007 
Moreover, the phylogenetic results of the Frost et al. study were largely consistent with previous morphological and molecular studies and where they differed, this was discussed with reference to the weight of evidence. (3) The claim that equally weighted parsimony assumes that all characters are evolving at equal rates has been shown to be false in both analytical and simulation studies. (4) The claimed "strong support" for marsupial frog monophyly is questionable. Several studies have also found marsupial frogs to be non-monophyletic. Wiens et al. (2005, Syst. Biol. 54, 719-748) recovered marsupial frogs as monophyletic, but that result was strongly supported only by Bayesian clade confidence values (which are known to overestimate support) and bootstrap support in his parsimony analysis was $<50 \%$. Further, in a more recent parsimony analysis of an expanded data set that included RAG-1 and the three traditional morphological synapomorphies of marsupial frogs, Wiens et al. (2006, Am. Nat. $168,579-596)$ also found them to be non-monophyletic. Although we attempted to apply the rule of monophyly to the naming of taxonomic groups, our phylogenetic results are largely consistent with conventional views even if not with the taxonomy current at the time of our writing. Most of our taxonomic changes addressed examples of non-monophyly that had previously been known or suspected (e.g., the non-monophyly of traditional Hyperoliidae, Microhylidae, Hemiphractinae, Leptodactylidae, Phrynobatrachus, Ranidae, Rana, Bufo; and the placement of Brachycephalus within "Eleutherodactylus", and Lineatriton within "Pseudoeurycea"), and it is troubling that Wiens and others, as evidenced by recent publications, continue to perpetuate recognition of non-monophyletic taxonomic groups that so profoundly misrepresent what is known about amphibian phylogeny.

(c) The Willi Hennig Society 2007.

Frost et al. (2006) reported the results of one of the largest phylogenetic studies of any vertebrate group to date. The analysis included 522 exemplar amphibian species, $>1.8$ million bp of DNA from three mitochondrial and five nuclear genes $(\bar{x}=3.7 \mathrm{kbp} /$ terminal; nearly 1800 new sequences were deposited in GenBank), and 152 phenotypic transformation series from larval and adult morphology (e.g., osteology, myology) and behavior coded for a subset of the terminals from across the diversity of amphibians (Haas, 2003).

Although the phylogenetic results were largely consistent with both conventional views of phylogeny (e.g., Ranoides is monophyletic, and embedded within a paraphyletic "Hyloidea", sensu lato; "Leptodactylidae" is polyphyletic, "Hyperoliidae" in the old sense of including Leptopelinae is non-monophyletic, as are "Microhylinae", "Bufo", and "Rana") and other recent studies (e.g., Roelants and Bossuyt, 2005), many of these phylogenetic results are logically inconsistent with traditionally recognized taxonomic groups. To remedy the communication problems caused by para- and polyphyletic groups we erected a monophyletic taxonomy based on consideration of both our results and the preponderance of all other published evidence. Disagreement among the 19 authors over analytical assumptions and methods did not prevent us from collaborating; our greatest hope was that our study, by way of providing a large amount of new evidence and a monophyletic taxonomy, would serve as a catalyst to stimulate workers to examine analytical methods and address lacunae in our understanding of amphibian evolution, and accelerate the development of a more complete understanding of not just amphibian evolutionary history, but also the analytical problems of general interest to all systematists. Moreover, we explicitly discussed the weak points of our study, including several of those raised by John J. Wiens
(2007) in his review and discussed below, to help focus future efforts to refute or corroborate our findings.

In light of both the magnitude and transparency of the Frost et al. (2006) monograph, we were surprised that Wiens, publishing in a journal, Quarterly Review of Biology, of which he is an editor, would describe the work as "a disaster" and "a waste" and recommend that readers "simply ignore this study" (Wiens, 2007). In response, we encourage readers to obtain a free electronic copy of Frost et al. (2006) via anonymous download at http://hdl.handle.net/2246/5781 to judge for themselves whether or not Wiens' conclusions are justified. We believe they are not, but we also believe that careful examination of the points raised by Wiens will benefit the broader systematics community because they exemplify many of the obstacles currently faced by large-scale revisionary studies. Unfortunately, our response was denied publication in the Quarterly Review of Biology on the grounds that "it is the policy of the journal not to print responses" (Albert D. Carlson, in litt.), so the original readership will not benefit from our arguments. Nevertheless, because the issues are sufficiently general, in order to move the discussion forward within the systematics community, here we respond directly to Wiens' specific criticisms ("fatal flaws") in the order in which they were originally presented.

\section{"The taxon sampling ... is inadequate for the generic-level changes that are made" and "Many changes are made without including the type species of genera"}

It is true that with only 522 ingroup species targeted to represent the 6091 species of living amphibians (Frost, 2007) there were obvious practical problems resulting from tissue availability and the need to maximize the spread of species within larger taxa of 
interest. And, although several of the taxonomic/nomenclatural issues did not become evident until the computationally intensive analytical part of the study was accomplished, the Frost et al. study did not exist in a vacuum. Although for purposes of formulating a monophyletic taxonomy for all amphibians we did in places extend beyond the sampled species and the data analyzed in our monograph, the proposed taxonomy also rests on a large diversity of previously published studies (e.g., Graybeal and Cannatella, 1995; Schäuble et al., 2000; Parra-Olea and Wake, 2001; Cunningham and Cherry, 2004; Pauly et al., 2004), many of which provided decisive evidence of non-monophyly but did not remedy the affected taxonomy.

As an example, we partitioned former "Bufo", a massive and world-wide, albeit paraphyletic, conglomeration of similar-appearing toads (Graybeal and Cannatella, 1995; Graybeal, 1997; Pauly et al., 2004), into a number of putatively monophyletic taxa, based not just on our results, but also on the existing published record as it portrayed taxa not included in our analysis. The taxonomy we formulated was discussed fully and is consistent with available molecular evidence as well as the preponderance of morphological evidence, such as it was, presented to justify the relevant species groups of various authors in Blair (1972). ${ }^{1}$ (It was, in fact, the publication by Blair, 1972, that set off our decision to address paraphyly at the generic level; it was clear that virtually all of the problems of paraphyly within "Bufo" were recognized in 1972 and allowed to continue to mislead the non-taxonomic community for the next 34 years by at least three generations of systematic biologists.) The total evidence results of Pramuk's (2006) study (published 2 weeks before Frost et al.) of South American bufonids are also consistent with our taxonomy, including recognizing the non-monophyly of "Bufo", with the exception of Rhinella + Rhamphophryne rendering Chaunus paraphyletic. And, this paraphyly was subsequently remedied by Chaparro et al. (2007) by nomenclaturally placing the species of " $\mathrm{Cha}$ unus" and, by implication, Rhamphophryne, into Rhinella, which thus redelimited is monophyletic. We assume that other improvements to the taxonomy of bufonids will be forthcoming by us and others as phylogenetic understanding continues to progress. We do not see this as instability but rather a reflection that

\footnotetext{
${ }^{1}$ Our taxonomy is not completely consistent with the total evidence (molecule + morphology) results of the older study of Graybeal (1997), although she also found "Bufo" to be non-monophyletic, but did not provide any taxonomic changes to remedy this. This does not bear on the issue at hand because: (1) her molecular data have been largely superseded except for $c-m o s$ (which we and others, e.g., Pauly et al., 2004; Pramuk, 2006, were remiss in not including in our analyses), and (2) the morphological transformation series used in her study were not published.
}

understanding evolution and providing a framework for communicating evolutionary relationships remains a work in progress. One hopes that other authors, like Chaparro and colleagues, will continue to move this shared endeavor forward with such alacrity. Although our treatment of "Bufo" was clearly the most extensive change at the generic level in our study, we made several others - all consistent with the preponderance of evidence as then understood and proposed not as the final word, but as an improved departure point for the enormous amount of comparative work still needed.

As for types, ideally, studies such as ours would include all name-bearing species (and all other species as well - consider that the inclusion of non-type species can alter the relative placement of type species and thus impact taxonomy; see below). In the absence of that ideal, Frost et al. based several nomenclatural changes on the existing phylogenetic hypotheses about the placement of type species relative to the sampled species. It is our view that, although inclusion of nomenclatural types is desirable, their absence should not prevent taxonomy from reflecting hypothesized evolutionary relationships, especially when the placement of namebearing types is substantially clear. In fact, this seems to be the sensible position taken by Wiens et al. (2005b) in their study of hylids and resulting generic revisions in which they did not include, among a variety of excluded type species, Hyla arborea, the type species of Hyla. We consider this sensible because of the evidence of previous work, even though the placement of this species determines the application of not only the generic name, Hyla, but, transitively, the application of the family group name Hylidae. The alternative is for taxonomy to seriously lag behind our understanding of evolutionary history, even when non-monophyly is evident, effectively hiding phylogenetic history from the broader community.

In the case of Ingerana, of which the type species is Ingerana tenasserimensis, our sole exemplar was Ingerana baluensis so we obviously did not test the monophyly of Ingerana, which was subsequently inferred by Bossuyt et al. (2006) to be polyphyletic, with "Ingerana" baluensis being in Ceratobatrachidae and Ingerana tenasserimensis in Dicroglossidae. Had we used solely Ingerana tenasserimensis, we presumably would have inferred the name-bearing type to be in Dicroglossidae, but would still have missed the polyphyly of "Ingerana". Regardless, the scope of this polyphyly remains unelucidated and the generic taxonomy unresolved (Frost, 2007). The over-arching issue is the need for denser taxon sampling, not just focusing on name-bearing types.

This was also the rationale for referring unsampled genera to families. In the case of Batrachophrynidae, to which Wiens objected specifically, Frost et al. (2006) obtained evidence regarding the placement of 
Caudiverbera and Telmatobufo such that a distinct family was required. [That the South American "leptodactylids" Caudiverbera and Telmatobufo are related to Australian frogs and not other South American frogs had also been found previously (e.g., San Mauro et al., 2005; Wiens et al., 2005b).] As Frost et al. explained, the preponderance of evidence at that time (Lynch, 1978; Burton, 1998; but see Sinsch and Juraske, 1995; Sinsch et al., 1995; who asserted a relationship to Telmatobius) suggested that Batrachophrynus was most closely related to those taxa. As such, although Batrachophrynus was not included in our analysis (and has yet to be sequenced by anyone), Frost et al. followed the International Code of Zoological Nomenclature (ICZN, 1999) in applying the oldest available family group name to the inclusive taxon, giving Batrachophrynidae. Subsequently, compelling evidence was presented that Batrachophrynus is most closely related to Telmatobius (larval morphology, Aguilar and Pacheco, 2005; karyotype, Córdova and Descailleaux, 2005), and therefore a member of Ceratophryidae (sensu Frost et al., 2006), which necessitated resurrection of the available name Calyptocephalellidae (see Frost, 2007) for Caudiverbera and Telmatobufo. Thus grows phylogenetic knowledge.

\section{"Bizarre omissions"}

The review identified two "bizarre omissions". The first is the recombination activating gene 1 (RAG-1), which was characterized by Wiens as "unquestionably the most widely used nuclear gene in amphibian phylogenetics". In fact, this characterization is untrue. The first study of amphibian systematics to use RAG-1 we are aware of was only published in 2003 (Biju and Bossuyt, 2003), and even now GenBank has more rhodopsin (1245 sequences) - a gene included by Frost et al. but excluded by Wiens et al. (2005a,b) - than RAG-1 (770 sequences) from systematics studies. ${ }^{2}$ Moreover, Wiens et al. (2005b) also omitted RAG-1 from their study and it was only with the importation of the RAG-1 GenBank sequences from Faivovich et al.

\footnotetext{
${ }^{2}$ Wiens did not specify the basis for his claim. Ours is based on the following search strings submitted to GenBank on February 5, 2007: "Amphibia" [Organism] and Rhodopsin[All Fields] NOT "Xenopus"[All Fields]. "Amphibia"[Organism] and ((RAG[All Fields] and 1[All Fields]) OR RAG1[All Fields] OR RAG-1[All Fields]) NOT "Xenopus"[All Fields]. Xenopus was excluded to focus searches on sequences from amphibian systematics studies. Limiting searches to September 1, 2005, the date Frost et al. (2006) was accepted for publication, there were 650 rhodopsin sequences and 366 RAG-1 sequences available on GenBank. Of the 770 RAG-1 sequences currently on GenBank, 301 were generated in the W. Wheeler lab as part of frog systematic projects independent of the Frost et al. project (Faivovich et al., 2005; Grant et al., 2006). These data will be included in future publications on amphibian phylogenetics.
}

(2005) that Wiens and colleagues (Smith et al., 2005; Wiens et al., 2006) applied RAG-1 to the study of frogs, even though Wiens had employed RAG-1 earlier in salamander studies (Chippindale et al., 2004; Wiens et al., 2005a) and presumably had the technology to generate these data. Under ideal circumstances we would have and should have included the RAG-1 data from other studies (e.g., Biju and Bossuyt, 2003; Chippindale et al., 2004; Faivovich et al., 2005), but this was impeded by issues of coordination during initial study design, data acquisition and management, analysis, and writing - much as we expect was the case with other large-scale phylogenetic analyses, such as that by Wiens et al. (2005b). But more importantly, Frost et al. analyzed the largest data set ever assembled to address the systematics of Amphibia, and it is unclear why an analysis of these data should be ignored due to the absence of a single locus. Phylogeneticists are only scratching the surface of the amphibian genome, and we foresee studies, not that far off, employing thousands of terminals and hundreds or thousands of genes, including RAG-1 and rhodopsin, as well as other genes applied to the study of amphibian phylogeny that neither Wiens nor we (except for M. Wilkinson) so far have employed, such as CXCR-4 and NCX-1 (Roelants and Bossuyt, 2005; Van Bocxlaer et al., 2006; Roelants et al., 2007). So, as time progresses our study will obviously be superseded, as, in fact, parts of it already have been (e.g., Glaw and Vences, 2006; Grant et al., 2006; Weisrock et al., 2006; Che et al., 2007).

Quoting the review (Wiens, 2007, p. 56):

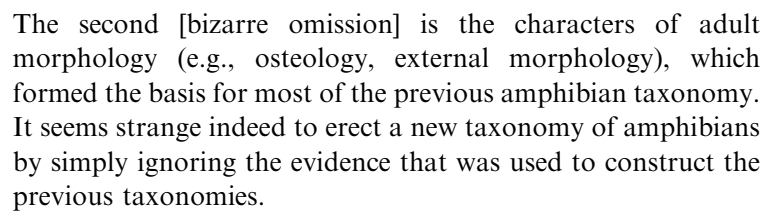
morphology (e.g., osteology, external morphology), which formed the basis for most of the previous amphibian taxonomy. It seems strange indeed to erect a new taxonomy of amphibians by simply ignoring the evidence that was used to construct the previous taxonomies.

Wiens' criticism misrepresents both Frost et al. and the state of amphibian systematics at the time of writing this paper. Frost et al. (2006, pp. 22-110) reviewed the morphological (and other) evidence for each group, as well as the obstacles that prevented the inclusion of all of the morphological data that had heretofore been proposed to characterize various parts of the overall tree-including, as previously noted by Haas (2003), that these data were rarely tied to specific specimen observations (e.g., see summaries of amphibian phylogenetics by Duellman and Trueb, 1986; Ford and Cannatella, 1993). At the time, the only published study to homologize phenotypic characters across a large portion of Amphibia by explicitly coding individual species for phylogenetic analysis is that of Haas (2003), and, as much as possible, those data were included by Frost et al. Although Haas's (2003) data are primarily larval, they also include several characters from adult 
morphology and behavior (see characters 137-156 of Haas, 2003). Further, the published evidence that was not included in our phylogenetic analysis was used explicitly to inform several of our taxonomic decisions. Indeed, Wiens also failed to mention that large parts of the previous taxonomy (e.g., former Leptodactylidae, Bufo, Ranidae) were widely understood (e.g., Duellman and Trueb, 1986; Ford and Cannatella, 1993; Graybeal, 1997; Haas, 2003; Darst and Cannatella, 2004; Wiens et al., 2005b) not to rest on synapomorphies at all, but upon social compact. Finally, as discussed at length by Frost et al., with a few exceptions, where morphological evidence existed our results based on mostly molecular data were consistent with prior hypotheses, and where they were not we drew attention to the disagreement. In some cases, taxa we named were not consistent with previously suggested hypotheses. In those cases, we considered that bold hypotheses were warranted in order to invite further work, so we took the step of providing formal taxonomic names. We suppose that we could have retarded the time line on production of our publication to include the morphological data sets published by Wiens et al. (2005a,b), but like so many real-life events in this fast-changing field, the first paper appeared after our computer-time-consuming analysis had been completed and the second appeared after our manuscript had been accepted. (These data sets will be addressed in an upcoming publication.) So, to make Frost et al.'s omission "bizarre" required Wiens to ignore the content of large parts of the paper and causes us to wonder how the omission of the morphological data set of Haas (2003) from the study by Wiens et al. (2005b) should be interpreted.

Moreover, we think that there are relatively few morphological synapomorphies that we did not include that are either inconsistent with our taxonomy or not already rejected by the preponderance of morphological evidence provided by Haas (2003). There are, of course, a few exceptions. The most recent and comprehensive morphological phylogenetic studies of caecilians (Wilkinson and Nussbaum, 1996; Wilkinson, 1997), inasmuch as they provide strong support for some relationships, are entirely consistent with our taxonomy.

Our taxonomy of salamanders is also consistent with the preponderance of morphological and molecular evidence as currently understood, with the possible exception of the placement of proteids and sirenids. We found Perennibranchia (=Sirenidae + Proteidae $)$ to form a clade as did Gao and Shubin (2001) in their combined analysis of morphological and molecular evidence. Our results resolved polytomies reported by Gao and Shubin in that we found Perennibranchia to form the sister taxon of all salamanders other than Cryptobranchoidei (= Cryptobranchidae + Hynobiidae). Wiens et al. (2005a) found Sirenidae in their parsimony analysis (morphological characters identified as paedomorphic were excluded) to be in a polytomy at the base of the tree and Proteidae to otherwise be in the position found by Frost et al. (2006). In their Bayesian analysis (morphological characters identified as paedomorphic were excluded) Wiens et al. (2005a) found Proteidae to form a group with Ambystomatidae (our sense) + Salamandridae, which together forms the sister taxon of Rhyacotritonidae + (Amphiumidae + Plethodontidae), and Sirenidae to be placed in the overall tree at the same relative position found by us (but, obviously without Proteidae forming its sister taxon). Resolution of these differences will be obtained by analysis of all of their data and ours taken together along with the fossil taxa of Gao and Shubin (2001) (excluded by Wiens et al., 2005a).

As for frogs, at the time of the writing of our study little had been published that attached specific synapomorphies broadly across all amphibians to particular species other than the study by Haas (2003). The narrative summary of evidence by Ford and Cannatella (1993) was, in effect, the gold standard. Frost et al. (2006, pp. 43-44) discussed the evidence presented by Ford and Cannatella (1993) for Leiopelma being the sister taxon of all other frogs except for Ascaphus, which was posited to be the sister taxon of this inclusive group. Ford and Cannatella (1993) suggested five synapomorphies of this grouping (their Leiopelmatanura): (1) elongate arms on the sternum; (2) loss of the ascending process of the palatoquadrate; (3) sphenethmoid ossifying in the anterior position; (4) exit of the root of the facial nerve from the braincase through the facial foramen, anterior to the auditory capsule, rather than via the anterior acoustic foramen into the auditory capsule; and (5) palatoquadrate articulating with the braincase via a pseudobasal process rather than a basal process. Characters 4 and 5 were polarized with respect to salamanders; the other three were apparently polarized on the assumption of their result, that Ascaphus is plesiomorphic and the sister taxon of remaining frogs, although this was not discussed. With respect to character 1 (the triradiate sternum) the parsimony cost of this transformation on the overall tree is identical if Ascaphidae and Leiopelmatidae are sister taxa and Alytidae and Bombinatoridae are sister taxa (the result favored by the molecular data). So, at first blush the morphological evidence of Ford and Cannatella (1993) that Ascaphus is the sister taxon of all other frogs comes down to two morphological transformations, these being inconsistent with our topology. Moreover, it is unlikely that the preponderance of morphological evidence supports the Ford and Cannatella topology; the fossils included in the analysis by Báez and Basso (1996) will have to be included in any comprehensive morphological study inasmuch as their character analysis of morphological characters also found Leiopelma and Ascaphus to form a monophyletic group. 
The morphological evidence provided by Haas (2003), and included in our analysis, supports the monophyly of Alytidae + Bombinatoridae, which was a feature of our results, but was rejected by Ford and Cannatella (1993) on the basis of fewer morphological synapomorphies. The placement of the non-controversial taxon Xenoanura (Pipidae + Rhinophrynidae) as the sister taxon of all frogs, excluding Leiopelmatidae (sensu lato), is consistent with the morphological evidence of Haas (2003) and our own predominantly molecular results and taxonomy. Indeed, the preponderance of the morphological evidence alone rejects Mesobatrachia of Ford and Cannatella (1993) and supports Lalagobatrachia (all frogs excluding Leiopelmatidae, sensu lato) of Frost et al. Interestingly, the morphology of Haas (2003) did not by itself recover the monophyly of Anomocoela, but was substantial enough to reject Mesobatrachia, as noted above. It was the molecular data, along with the morphology of Haas (2003) that supported the monophyly of Anomocoela + Neobatrachia (a non-controversial clade in terms of older notions of morphology, e.g., Noble, 1931). Obviously, we could go on and on inasmuch as we have just scratched the surface of a discussion already presented extensively by Frost et al. (2006, pp. 22-141). So, to avoid moving this discussion beyond the scope of this reply, we will just note that once discussion of morphological evidence takes up Neobatrachia (a bewildering array of almost all frogs), the morphological characters become much more difficult to delimit and apply, as explained in Frost et al. For this reason we address here just a few exemplar sections that we think may be relevant to Wiens' criticisms.

The morphological evidence for the various groups within the former "Leptodactylidae" has never been summarized in a way that allowed straightforward comparison with taxonomic groups not considered to be "leptodactylids". Nevertheless, neither of the two systems of subfamilies that found common application in the herpetological community were based rigorously on synapomorphy schemes: (1) Heyer (1975) formalized by Laurent (1986), and (2) Lynch (1971) summarized by Duellman and Trueb (1986). The former was based upon a similarity clustering method among genera assumed for purposes of analysis to be monophyletic, and the latter recognized some groups based on synapomorphy (Leptodactylinae: bony sternum; Ceratophryinae: a number of apomorphies), along with a basal, presumably paraphyletic Telmatobiinae for which no synapomorphies were suggested. When one compares the groups that we elucidated on the basis of molecular data and the morphology of Haas (2003), particularly as augmented by Grant et al. (2006), with the prior understanding of relationships (characterized as "grossly paraphyletic" by Ford and Cannatella, 1993, p. 108) we believe we have provided a framework for the cogent comparative study of morphology and improved outgroup delimitation for less inclusive studies. We consider this to represent considerable progress in the understanding of this large and extremely diverse assemblage.

Although the recent total evidence study of morphology and molecules by Scott (2005), which focused primarily on African taxa, provided for additional progress in our understanding of ranoid evolutionary morphology and relationships, this group remains problematic at lower taxonomic levels, such as among the tropical Asian species of Ranidae. One need only look at the summaries of morphological character distributions provided by Dubois (1992) and Ford and Cannatella (1993) to realize that relatively few characters are involved in the traditional morphological descriptions of these taxa and many of these are extremely difficult to individuate [e.g., toe-disc size, toe-disc grooving, degree of webbing, degree of (possibly seasonal) development of brachial glandular areas]. Much work is needed in the morphology of Ranoides. In fact, all neobatrachian frogs need extensive study before the morphological diversity of frogs is even substantially described, much less understood with respect to evolutionary history.

Although in principle we agree that morphology is an area of amphibian systematics in need of detailed study, we find little practical merit in Wiens' complaint that we did not use the characters of traditional morphology on which the previous, misleading taxonomy was based. During the earlier prephylogenetic era the method that underlay most taxonomic reasoning was subjective evaluation of overall similarity - along with strong doses of authoritarianism-resulting in special pleading for particular characters. Similar species were grouped under common generic names (e.g., "Bufo", "Rana") and ones that stood out as really different were included in taxa of higher ranks, without knowledge of, or regard for, phylogenetic relationships. In fact, to characterize the previous taxonomy as "based" on morphology is to conflate the traditional practice of subjective ordering by overall similarity or special pleading for particular characters with the search for morphological synapomorphies. Unfortunately, the search for morphological synapomorphies is something that continues to be insufficiently addressed in the published record of amphibian systematics. Nevertheless, most of our monophyletic taxonomy is consistent with the preponderance of morphology identified as synapomorphic that had been published up to the time of our study, so the practical problems appear to us to be minimal.

We are indebted to the workers of times past who constructed much of the taxonomy that we grew up with (e.g., C. Bonaparte, G. A. Boulenger, E. D. Cope, A. Duméril, E. R. Dunn, L. Fitzinger, A. Günther, R. Laurent, G. K. Noble, H. W. Parker, W. Peters, and E. H. Taylor). Their influential contributions brought us 
to the time of formal phylogenetic inference, when the age of informed speculation gave way to the era of data analysis and evidentiary transparency. Our ongoing concern is that we should embrace monophyly as the organizing principle of systematics and not be bound unduly by the past, and not get stuck with a taxonomy that we have recognized since at least the early 1970s is substantially flawed (and which could and should therefore have been substantially improved 30 years ago).

\section{"Questionable methods"}

Wiens alleged that Frost et al. employed "questionable methods" and highlighted his own study of hylids (Wiens et al., 2005b) as exemplifying "modern [and presumably unquestionable] methods". Specifically, and despite the fact that Wiens et al. (2005b, 2006) also employed equally weighted parsimony (together with a Bayesian method, or alone) (Wiens et al., 2006, suppl. data 2), he criticized the use of equally weighted parsimony, which he claimed "assumes that all characters are evolving at equal rates, an assumption that is simply false". No citation was given, and this characterization of equally weighted parsimony has long been known to be incorrect, as demonstrated by simulations (e.g., Kolaczkowski and Thornton, 2004) and analytical studies (e.g., Tuffley and Steel, 1997; Goloboff, 2003).

Regarding our methods, Frost et al. performed a total evidence analysis of DNA sequences and morphology in the computer program POY (Wheeler et al., 2006), which employs direct optimization algorithms to search for the optimal alignment(s) of DNA sequence (e.g., Wheeler, 1996; Wheeler et al., 2006). The "modern methods" of Wiens et al. (2005b) included basing alignments of DNA sequences on single NeighborJoining guide trees in ClustalX (Thompson et al., 1997) followed by idiosyncratic data elimination and "by eye" adjustment without an explicit optimality criterion and tree-searching under a different set of transformation costs than used for the alignment (a procedure certainly applied widely in the systematics community, but hardly a "modern method"). Conversely, the method we employed, direct optimization, evaluates nucleotide homology dynamically according to an explicit optimality criterion (e.g., parsimony, maximum likelihood), a procedure that has long been recognized as optimal (e.g., Sankoff, 1975; Sankoff et al., 1976, 1982; Felsenstein, 1988; Hein, 1989; Thorne and Kishino, 1992; Slowinski, 1998) but is only beginning to attract attention in the broader systematics community (e.g., Fleissner et al., 2005; Lunter et al., 2005; Redelings and Suchard, 2005; Roshan et al., 2006). Regardless, given the deep methodological disagreements in systematics, it would be naive to expect everyone to agree with our approach (e.g., see Ogden and Rosenberg, 2007). It is therefore relevant that all data are freely and anonymously available for download at http://research.amnh. org/herpetology/downloads.html, and all DNA sequences are deposited on GenBank.

\section{"Clearly erroneous results"}

Wiens also charged that "In many cases, the problematic methods seem to have led to clearly erroneous results", which he substantiated by citing his own "strong support" for the monophyly of marsupial frogs (Wiens et al., 2005b) in opposition to Frost et al.'s finding that they are polyphyletic. However, the "strong support" noted refers only to the Bayesian support, as the bootstrap support for this clade is $<50 \%$ in Wiens et al.'s (2005b, p. 733, fig. 5) parsimony analysis of molecules and morphology (but as noted above, excluding RAG-1 from the data set). It has been shown that Bayesian clade confidence values consistently overestimate clade support (Cummings et al., 2003; Erixon et al., 2003; Simmons et al., 2004; Taylor and Piel, 2004), and our results were hardly unique; earlier studies (e.g., Darst and Cannatella, 2004; Faivovich et al., 2005) agree with ours that marsupial frogs are not monophyletic. Most significantly, Wiens failed to disclose that he and coauthors (Wiens et al., 2006, supplementary information: 11, including RAG-1 data from Faivovich et al., 2005, as well as the traditional three morphological synapomorphies of marsupial frogs) also found marsupial frogs to be non-monophyletic in their parsimony analysis. Citing time constraints, Wiens et al. (2006) did not include marsupial frogs in their Bayesian analysis, so it is unclear if they would be found to be monophyletic in that assumption framework. However, given that both the preponderance of the evidence (in an equally weighted parsimony framework) and most recent publications have refuted marsupial frog monophyly, it is clear that there is no basis to reject our result as "clearly erroneous". Nevertheless, in the interest of transparency, we noted places in our overall tree where our evidence did not sufficiently test previously published results, such as in hylids or plethodontid salamanders, where for purposes of recognizing taxonomic groups we accepted the results of Faivovich et al. (2005) for hylids and the shared generalizations of Chippindale et al. (2004) and Macey (2005) for plethodontids.

Wiens concluded his review by allowing that "some of the phylogenetic results and taxonomic changes will almost certainly prove to be correct'". But he went on to ask, "how does one know which are right and which are not?" This, of course, is the eternal question of empirical inference, but if the growing body of evidence and literature, including subsequent studies using different data, different methods, and different assumptions, are 
any indication (Van Bocxlaer et al., 2006; Roelants et al., 2007), the bulk of Frost et al.'s phylogenetic hypotheses are "correct". In fact, those recent publications adopted our taxonomy with modifications where evidence demanded it, apparently because these authors found a monophyletic taxonomy to be more useful than the non-monophyletic one that went before. Under Wiens' view we should presumably "simply ignore" those studies as well, but we think that the community of systematic biologists is neither immune to data nor susceptible to such rhetoric.

We are troubled that Wiens and some others continue to perpetuate a taxonomy that is so deeply at odds with the empirical understanding of amphibian phylogeny. As summarized by Frost et al. the non-monophyly of many of these taxa has been known or suspected for years (e.g., Leptodactylidae, Ranidae, Microhylinae, Bufo, Pseudoeurycea, Rana; the placement of Brachycephalus within Eleutherodactylus), and yet several workers continue to employ a non-monophyletic taxonomy-indeed, the evidence of subsequent publication is that our paper has made them embrace non-monophyletic taxonomies even more strongly. Although Wiens (2007, p. 56) derided our expectation of sociological resistance to monophyletic taxonomies, this is precisely what we see. Wiens' review of our work and subsequent publications by him and others suggest that they believe the fact that we might be wrong about parts of the amphibian tree is good reason to ignore our work and retain non-monophyletic taxonomies in the face of overwhelming evidence. For example, Wiens et al. (2007) found the plethodontid salamander taxa Ixalotriton, Lineatriton and Parvimolge to be nested within Pseudoeurycea, and Lineatriton to be polyphyletic, as suggested previously by Parra-Olea and coauthors (Parra-Olea and Wake, 2001; Parra-Olea, 2002) (see Frost et al., 2006, p. 178, for comments on Parvimolge, Ixalotriton and Lineatriton), and yet Wiens et al. declined to follow Frost et al. in placing Lineatriton and Ixalotriton into the synonymy of Pseudoeurycea. Further, they did not follow their own evidence that Parvimolge, additionally, belongs in the synonymy of Pseudoeurycea, even though their biogeographical analysis required the acceptance of this overall phylogenetic hypothesis. Others have also demonstrated their sociological adherence to paraphyly. For instance: (1) Duellman et al. (2006b) continued to treat marsupial frogs as hylids, even though Darst and Cannatella (2004), Faivovich et al. (2005), Wiens et al. (2005b), and Frost et al. (2006) found that the marsupial frogs were not within Hylidae; (2) Duellman et al. (2006a) retained Eleutherodactylus in Leptodactylidae in spite of the fact that no morphological (e.g., Lynch, 1971, 1973) or molecular evidence supports this as a taxon and there is overwhelming evidence that "Leptodactylidae" in this non-monophyletic sense is detrimental to communica- tion of frog relationships and composed of several groups that for many years were real candidates for monophyly (e.g., Hylodinae, Ceratophryinae); (3) Lehr and Trueb (2007) retained Microhylinae for a collection of both New and Old World frogs, even though no morphological synapomorphy has ever been suggested and the taxonomy we proposed is consistent with current understanding that the old "Microhylinae" is polyphyletic with independently evolved Old World (Microhylinae) and New World (Gastrophryninae) groups as well as a number of other genera formerly assigned to "Microhylinae" of uncertain or basal placement (e.g., Synapturanus) (Frost et al., 2006; Van Bocxlaer et al., 2006; Roelants et al., 2007). None of these authors who embraced non-monophyletic groups presented evidence for their groupings; none exists. And none of these authors explained why, in light of available data and current knowledge, they embraced a taxonomy that is so misleading to anyone outside of amphibian systematics.

In the same vein of response by those resisting change, it has been argued that a compromise solution is to remedy generic non-monophyly by formally treating those taxa that render a genus paraphyletic as subgenera. In the case of Bufo specifically, workers have recommended considering as subgenera within Bufo those taxa that render Bufo non-monophyletic, rendering such taxa as Bufo (Rhinella) marinus (Smith and Chiszar, 2006; H.M. Smith, in litt.; D.B. Wake, in litt.). However, this approach has effects seemingly unforeseen by these authors. Minimally, in order to make the traditional Bufo monophyletic the following traditionally and more-or-less universally recognized genera would have to become subgenera within Bufo: Ansonia, Bufo, Capensibufo, Didynamipus, Mertensophryne, Nectophryne, Nectophrynoides, Pedostibes, Pelophryne, Rhamphophryne, Schismaderma, Werneria and Wolterstorffina, as well as the taxa that we named or resurrected (e.g., Amietophrynus, Anaxyrus, Duttaphrynus, Epidalea, Ingerophrynus, Nannophryne, Ollotis, Peltophryne, Pseudepidalea, Rhaebo, Rhinella and Vandijkophrynus). In addition, a number of genera not sampled by Frost et al. but which appear to be nested within the traditional Bufo would presumably also need to be treated as subgenera: Adenomus, Altiphrynoides, Andinophryne, Bufoides, Churamiti, Crepidophryne, Laurentophryne, Nimbaphrynoides, Parapelophryne and Pseudobufo. The inclusion of all of these diverse taxa within Bufo would significantly alter both the names of the species associated with those genera as well as the traditional concept of Bufo as a similarity cluster, while also obscuring phylogenetic relationships and other aspects of biology (e.g., biogeographical patterns). In fact, this "solution" would require a large number of nomenclatural changes outside of North America and Europe and would be seen by workers from those 
regions as an unwarranted change in familiar taxonomy. The number of species assigned to Bufo would climb to over 370 , "saving" $\approx 260$ species that we transferred out of the unwieldy and paraphyletic "Bufo", but inadvertently requiring the assignment to a monophyletic Bufo of over 100 other species formerly assigned to other familiar, albeit not North American or European, genera. Although this would meet the desire of a few North American and European workers to continue referring to local taxa with familiar names regardless of how this affects nomenclatural continuity in other regions, we do not believe this achieves the ultimate goals of an internationally inclusive scientific taxonomy, nor, even more importantly, does it foster the growth of systematic knowledge.

Concern for the broader community of ecologists, conservation biologists, environmental policy makers and other non-systematists is on occasion cited as a basis for this refusal to alter outdated taxonomies (e.g., Smith and Chiszar, 2006). However, it is precisely the recognition of our responsibility to this larger community that requires us to bring taxonomy and phylogeny into greater agreement. Those workers rely on the taxonomy that systematists provide to design their studies, interpret their results, and craft conservation policy, and we believe this requires systematists to set aside personal preferences and authoritarianism and provide the taxonomy that best reflects our current understanding of phylogeny. This is true for all groups but is especially urgent in the case of amphibians due to the catastrophic declines observed around the globe. This urgency certainly does not absolve systematists from being careful and precise in applying their results, whether in taxonomy or any other area (e.g., conservation, biogeography), but decisions should be based on evidence, not mere conviction or disbelief. To "simply ignore" this study or any other contribution is hardly in keeping with scientific principles or sound judgment. Moreover, Frost et al. (2006) analyzed the largest data set ever assembled to study the systematics of Amphibia and surveyed virtually all other systematic studies of amphibians for evidence of monophyletic groups. If this is not adequate to justify changing the taxonomy to one that is consistent with evolutionary history, what is?

\section{References}

Aguilar, C., Pacheco, V., 2005. Contribución de la morfología bucofaríngea larval a la filogenia de Batrachophrynus y Telmatobius. In: Lavilla, E.O., De la Riva, I. (Eds.), Estudio Sobre las Ranas Andinas de los Géneros Telmatobius y Batrachophrynus (Anura: Leptodactylidae). Monografías de Herpetología, 7. Asociación Herpetológica Española, Valencia, pp. 219-238.

Báez, A.M., Basso, N.G., 1996. The earliest known frogs of the Jurassic of South America: review and cladistic appraisal of their relationships. Münchner Geowissenschaft. Abh.(A) 30, 131-158.
Biju, S.D., Bossuyt, F., 2003. New frog family from India reveals an ancient biogeographical link with the Seychelles. Nature 425, 711714.

Blair, W.F., ed., 1972. Evolution in the Genus Bufo. University of Texas Press, Austin, TX.

Bossuyt, F., Brown, R.M., Hillis, D.M., Cannatella, D.C., Milinkovitch, M.C., 2006. Phylogeny and biogeography of a cosmopolitan frog radiation: Late Cretaceous diversification resulted in continent-scale endemism in the family Ranidae. Syst. Biol. 55, 579-594.

Burton, T.C., 1998. Pointing the way: the distribution and evolution of some characters of the finger muscles of frogs. Am. Mus. Novit. $3229,1-13$.

Chaparro, J.C., Pramuk, J.B., Gluesenkamp, A.G., 2007. A new species of arboreal Rhinella (Anura: Bufonidae) from cloud forest of southeastern Peru. Herpetologica 63, 203-212.

Che, J., Pang, J., Zhao, H., Wu, G., Zhao, E., Zhang, Y., 2007. Phylogeny of Raninae (Anura: Ranidae) inferred from mitochondrial and nuclear sequences. Mol. Phylogenet. Evol. 42, 1-13.

Chippindale, P.T., Bonett, R.M., Baldwin, A.S., Wiens, J.J., 2004. Phylogenetic evidence for a major reversal of life-history evolution in plethodontid salamanders. Evolution 58, 2809-2822.

Córdova, J.H., Descailleaux, J., 2005. El análisis cladistico preliminar de los cariotipos de cinco especies de Telmatobius y dos de Batrachophrynus no apoya su separación genérica. In: Lavilla, E.O., De la Riva, I. (Eds.), Estudio Sobre las Ranas Andinas de los Géneros Telmatobius y Batrachophrynus (Anura: Leptodactylidae). Monografías de Herpetología, 7. Asociación Herpetológica Española, Valencia, pp. 187-217.

Cummings, M., Handley, S., Myers, D., Reed, D., Rokas, A., Winka, K., 2003. Comparing bootstrap and posterior probability values in the four-taxon case. Syst. Biol. 52, 477-487.

Cunningham, M., Cherry, M.I., 2004. Molecular systematics of African 20-chromosome toads (Anura: Bufonidae). Mol. Phylogenet. Evol. 32, 671-685.

Darst, C.R., Cannatella, D.C., 2004. Novel relationships among hyloid frogs inferred from $12 \mathrm{~S}$ and $16 \mathrm{~S}$ mitochondrial DNA sequences. Mol. Phylogenet. Evol. 31, 462-475.

Dubois, A., 1992. Notes sur la classification des Ranidae (Amphibiens anoures). Bull. Mens. Soc. Linn. Lyon 61, 305-352.

Duellman, W.E., Trueb, L., 1986. Biology of Amphibians. McGrawHill Co., New York.

Duellman, W.E., Lehr, E., Venegas, P.J., 2006a. Two new species of Eleutherodactylus (Anura: Leptodactylidae) from the Andes of northern Peru. Zootaxa 1285, 51-64.

Duellman, W.E., Trueb, L., Lehr, E., 2006b. A new species of marsupial frog (Anura: Hylidae: Gastrotheca) from the Amazon slopes of the Cordillera Oriental in Peru. Copeia 2006, 595-603.

Erixon, P., Svennblad, B., Britton, T., Oxelman, B., 2003. Reliability of Bayesian posterior probabilities and bootstrap frequencies in phylogenetics. Syst. Biol. 52, 665-673.

Faivovich, J., Haddad, C.F.B., Garcia, P.C.A., Frost, D.R., Campbell, J.A., Wheeler, W.C., 2005. Systematic review of the frog family Hylidae, with special reference to Hylinae: a phylogenetic analysis and taxonomic revision. Bull. Am. Mus. Nat. Hist. 294, $1-240$.

Felsenstein, J., 1988. Phylogenies from molecular sequences: inference and reliability. Annu. Rev. Genet. 22, 521-565.

Fleissner, R., Metzler, D., Von Haeseler, A., 2005. Simultaneous statistical multiple alignment and phylogeny reconstruction. Syst. Biol. 54, 548-561.

Ford, L.S., Cannatella, D.C., 1993. The major clades of frogs, Herpetol. Monogr. 7, 94-117.

Frost, D.R., 2007. Amphibian Species of the World: An Online Reference. Version 5.0. (1 February 2007). Electronic database accessible at http://research.amnh.org/herpetology/amphibia/index. $\mathrm{php} /$. American Museum of Natural History, New York. 
Frost, D.R., Grant, T., Faivovich, J., Bain, R.H., Haas, A., Haddad, C.F.B., de Sá, R.O., Channing, A., Wilkinson, M., Donnellan, S.C., Raxworthy, C.J., Campbell, J.A., Blotto, B.L., Moler, P., Drewes, R.C., Nussbaum, R.A., Lynch, J.D., Green, D.M., Wheeler, W.C., 2006. The amphibian tree of life. Bull. Am. Mus. Nat. Hist. 297, 1-370.

Gao, K., Shubin, N.H., 2001. Late Jurassic salamanders from northern China. Nature 410, 574-577.

Glaw, F., Vences, M., 2006. Phylogeny and genus-level classification of mantellid frogs (Amphibia, Anura). Org. Divers. Evol. 6, 236-253.

Goloboff, P.A., 2003. Parsimony, likelihood, and simplicity. Cladistics 19, 91-103.

Grant, T., Frost, D.R., Caldwell, J.P., Gagliardo, R., Haddad, C.F.B., Kok, P.J.R., Means, D.B., Noonan, B.P., Schargel, W.E., Wheeler, W.C., 2006. Phylogenetic systematics of dart-poison frogs and their relatives (Amphibia: Athesphatanura: Dendrobatidae). Bull. Am. Mus. Nat. Hist. 299, 1-262.

Graybeal, A., 1997. Phylogenetic relationships of bufonid frogs and tests of alternate macroevolutionary hypotheses characterizing their radiation. Zool. J. Linn. Soc. 119, 297-338.

Graybeal, A., Cannatella, D.C., 1995. A new taxon of Bufonidae from Peru, with descriptions of two new species and a review of the phylogenetic status of supraspecific bufonid taxa. Herpetologica $51,105-131$.

Haas, A., 2003. Phylogeny of frogs as inferred from primarily larval characters (Amphibia: Anura). Cladistics 19, 23-90.

Hein, J., 1989. A new method that simultaneously aligns and reconstructs ancestral sequences for any number of homologous sequences, when the phylogeny is given. Mol. Phylogenet. Evol. 6, 649-668.

Heyer, W.R., 1975. A preliminary analysis of the intergeneric relationships of the frog family Leptodactylidae. Smithson. Contrib. Zool. 199, 1-55.

International Commission on Zoological Nomenclature, 1999. International Code of Zoological Nomenclature, 4th edn. International Trust for Zoological Nomenclature, London.

Kolaczkowski, B., Thornton, J.W., 2004. Performance of maximum parsimony and likelihood phylogenetics when evolution is heterogeneous. Nature 431, 980-984.

Laurent, R.F., 1986. Sous classe des lissamphibiens (Lissamphibia). In: Grassé, P., Delsol, M. (Eds.), Traité de Zoologie. Anatomie, Systematique, Biologie, Vol. 14. (Batraciens). Fascicule 1b. Masson, Paris, pp. 594-797.

Lehr, E., Trueb, L., 2007. Diversity among New World microhylid frogs (Anura: Microhylidae): morphological and osteological comparisons between Nelsonophryne (Günther 1901) and a new genus from Peru. Zool. J. Linn. Soc. 149, 583-609.

Lunter, G., Miklós, I., Drummond, A., Jensen, J.L., Hein, J., 2005. Bayesian coestimation of phylogeny and sequence alignment. BMC Bioinformatics 6, 83 .

Lynch, J.D., 1971. Evolutionary relationships, osteology, and zoogeography of leptodactyloid frogs. Misc. Publ. Mus. Nat. Hist. Univ. Kansas 53, 1-238.

Lynch, J.D., 1973. The transition from archaic to advanced frogs. In: Vial, J.L. (Ed.), Evolutionary Biology of the Anurans: Contemporary Research on Major Problems. University of Missouri Press, Columbia, MO, pp. 133-182.

Lynch, J.D., 1978. A re-assessment of the telmatobiine leptodactylid frogs of Patagónia. Occas. Pap. Mus. Nat. Hist. University Kansas $72,1-57$.

Macey, J.R., 2005. Plethodontid salamander mitochondrial genomics: a parsimony evaluation of character conflict and implications for historical biogeography. Cladistics 21, 194-202.

Noble, G.K., 1931. The Biology of the Amphibia. McGraw-Hill, New York.

Ogden, T.H., Rosenberg, M.S., 2007. Alignment and topological accuracy of the direct optimization approach via POY and traditional phylogenetics via ClustalW + PAUP. Syst. Biol. 56, $182-193$.

Parra-Olea, G., 2002. Molecular phylogenetic relationships of Neotropical salamanders of the genus Pseudoeurycea. Mol. Phylogenet. Evol. 22, 234-246.

Parra-Olea, G., Wake, D.B., 2001. Extreme morphological and ecological homoplasy in tropical salamanders. Proc. Natl Acad. Sci. USA 98, 7888-7891.

Pauly, G.B., Hillis, D.M., Cannatella, D.C., 2004. The history of Nearctic colonization: molecular phylogenetics and biogeography of the Nearctic toads (Bufo). Evolution 58, 2517-2535.

Pramuk, J.B., 2006. Phylogeny of South American Bufo (Anura: Bufonidae) inferred from combined evidence. Zool. J. Linn. Soc. 146, 407-452.

Redelings, B.D., Suchard, M.A., 2005. Joint Bayesian estimation of alignment and phylogeny. Syst. Biol. 54, 401-418.

Roelants, K., Bossuyt, F., 2005. Archaeobatrachian paraphyly and Pangaean diversification of crown-group frogs. Syst. Biol. 54, 111126.

Roelants, K., Gower, D.J., Wilkinson, M., Loader, S.P., Biju, S.D., Guillaume, K., Moriau, L., Bossuyt, F., 2007. Global patterns of diversification in the history of modern amphibians. Proc. Natl Acad. Sci. USA 104, 887-892.

Roshan, U., Livesay, D.R., Chikkagoudar, S., 2006. Improving progressive alignment for phylogeny reconstruction using parsimonious guide-trees. Sixth IEEE Symp. Bioinformatics Bioengineering (BIBE) 2006, 159-194.

San Mauro, D., Vences, M., Alcobendas, M., Zardoya, R., Meyer, A., 2005. Initial diversification of living amphibians predated the breakup of Pangaea. Am. Nat. 165, 590-595.

Sankoff, D., 1975. Minimal mutation trees of sequences. SIAM. J. Appl. Math. 28, 35-42.

Sankoff, D., Cedergren, R.J., Lapalme, G., 1976. Frequency of insertion-deletion, transversion, and transition in evolution of $5 \mathrm{~S}$ ribosomal RNA. J. Mol. Evol. 7, 133-149.

Sankoff, D., Cedergren, R.J., McKay, W., 1982. A strategy for sequence phylogeny research. Nucleic Acids Res. 10, 421-431.

Schäuble, C.S., Moritz, C., Slade, R.W., 2000. A molecular phylogeny for the frog genus Limnodynastes (Anura: Myobatrachidae). Mol. Phylogenet. Evol. 16, 379-391.

Scott, E., 2005. A phylogeny of ranid frogs (Anura: Ranoidea: Ranidae), based on a simultaneous analysis of morphological and molecular data. Cladistics 21, 507-574.

Simmons, M.P., Pickett, K.M., Miya, M., 2004. How meaningful are Bayesian support values? Mol. Phylogenet. Evol. 21, 188199.

Sinsch, U., Juraske, N., 1995. Reassessment of central Peruvian Telmatobiinae (genera Batrachophrynus and Telmatobius) II. Allozymes and phylogenetic relationships. Alytes 13, 52-66.

Sinsch, U., Salas, A.W., Canales, V., 1995. Reassessment of central Peruvian Telmatobiinae (genera Batrachophrynus and Telmatobius) I. Morphometry and classification. Alytes 13, 14-44.

Slowinski, J.B., 1998. The number of multiple alignments. Mol. Phylogenet. Evol. 10, 264-266.

Smith, H.M., Chiszar, D., 2006. Dilemma of name-recognition: why and when to use new combinations of scientific names. Herpetol. Conserv. Biol. 1, 6-8.

Smith, S.A., Stephens, P.R., Wiens, J.J., 2005. Replicate patterns of species richness, historical biogeography, and phylogeny in Holarctic treefrogs. Evolution 59, 2433-2450.

Taylor, D.J., Piel, W.H., 2004. An assessment of accuracy, error, and conflict with support values from genome-scale phylogenetic data. Mol. Biol. Evol. 21, 1534-1537.

Thompson, J.D., Gibson, T.J., Plewniak, F.J., Higgins, D.G., 1997. The ClustalX Windows interface: flexible strategies for multiple sequence alignment aided by quality analysis tools. Nucleic Acids Res. 24, 4876-4882. 
Thorne, J.L., Kishino, H., 1992. Freeing phylogenies from artifacts of alignment. Mol. Biol. Evol. 9, 1148-1162.

Tuffley, C., Steel, M., 1997. Links between maximum likelihood and maximum parsimony under a simple model of site substitution. Bull. Math. Biol. 59, 581-607.

Van Bocxlaer, I., Roelants, K., Biju, S.D., Nagaraju, J., Bossuyt, F., 2006. Late Cretaceous vicariance in Gondwanan amphibians. PLoS One 1, 1-6.

Weisrock, D.W., Papenfuss, T.J., Macey, T.R., Litvinchuk, S.N., Polymeni, R., Ugartas, I.H., Zhao, E., Jowkar, H., Larson, A., 2006. A molecular assessment of phylogenetic relationships and lineage accumulation rates with the family Salamandridae (Amphibia, Caudata). Mol. Phylogenet. Evol. 41, 368-383.

Wheeler, W.C., 1996. Optimization alignment: the end of multiple sequence alignment in phylogenetics? Cladistics 12, 1-9.

Wheeler, W.C., Aagesen, L., Arango, C.P., Faivovich, J., Grant, T., D'Haese, C.A., Janies, D., Smith, W.L., Varón, A., Giribet, G., 2006. Dynamic Homology and Phylogenetic Systematics: A Unified Approach Using POY. American Museum of Natural History, New York.

Wiens, J.J., 2007. Book review: The amphibian tree of life. Q. Rev. Biol. 82, 55-56.
Wiens, J.J., Bonett, R.M., Chippindale, P.T., 2005a. Ontogeny discombobulates phylogeny: paedomorphosis and higher-level salamander relationships. Syst. Biol. 54, 91-110.

Wiens, J.J., Fetzner, J.W., Parkinson, C.L., Reeder, T.W., 2005 b. Hylid frog phylogeny and sampling strategies for speciose clades. Syst. Biol. 54, 719-748.

Wiens, J.J., Graham, C.H., Moen, D.S., Smith, S.A., Reeder, T.W., 2006. Evolutionary and ecological causes of the latitudinal diversity gradient in hylid frogs: treefrogs unearth the roots of high tropical diversity. Am. Nat. 168, 579-596.

Wiens, J.J., Parra-Olea, G., García-París, M., Wake, D.B., 2007. Phylogenetic history underlies elevational biodiversity patterns in tropical salamanders. Proc. R. Soc. London Series B, 274, 918 928.

Wilkinson, M., 1997. Characters, congruence and quality: a study of neuroanatomical and traditional data in caecilian phylogeny. Biol. Rev. Cambridge Philos. Soc. 72, 423-470.

Wilkinson, M., Nussbaum, R.A., 1996. On the phylogenetic position of the Uraeotyphlidae (Amphibia: Gymnophiona). Copeia 1996, $550-562$. 